\title{
Full-fledged level of physical training of a specialist is an integral part of stability of a work process
}

\author{
Aleksey Y. Polyakov* \\ Ufa State Petroleum Technological University, Branch of the University in the City of Oktyabrsky, Russian Federation
}

\begin{abstract}
Professional training of specialist in the environment of modern institution of higher technical education assumes not only formation of certain skills and abilities that the future specialist shall be ready to apply in their professional life, but also formation of a set of personal traits appropriate of the modern technical specialist. One of such traits is a full-fledged level of physical fitness, expressed in responsible attitude to one's health and understanding the fact that its preservation in not only a matter of qualified actualization of professional life according to one's chosen profession, but also that of stable operation of the company, full-fledged interaction between the members of the collective during performance of their functions.
\end{abstract}

\section{Introduction}

Currently, unfortunately, in many institutions of higher technical education, physical education is deemed as being one of general education subjects, and even its instructors see it as a peripheral part of the educational process that has no serious influence on personal development of the future specialist. On the one hand, various games, Dorm Olympics and other competitions are held in various sports within the confines of physical education. On the other hand, they all happen somewhat removed from one of the leading aspects of the modern higher professional education, its integrity: the concept of integrity supposes multifaceted training of the future specialist that touches upon every aspect of their future professional life, including such topics as labor safety, health preservation and accident prevention. Such training is also one of the objectives of physical education as an academic activity and shall be implemented depending on the nature of the student's major. Consequently, this is not about general, but rather applied physical education, that is, one that is performed in relation to the future professional life of a student.

Professional-purpose physical education (PPPE) is a subsystem of physical education that provides formation of a set of personal traits and attributes that have a significant value for the professional life within the profession.

This subsystem is at the junction of several fields of science: physical education, medicine, pedagogy, psychology and the field of knowledge to which the student's future profession pertains [1].

The main objective of the professional-purpose physical education of students in an institution of higher technical education is to facilitate mastering the profession in those aspects that require psychophysical preparedness to productive labor. To attain this objective, the PPPE is allotted a task to form professionally-important personal traits of the technical specialists with the help of tools and methods of physical education. At various moments, this question was analyzed by V.I. Andreyev, V.P. Polyansky, R.T. Rayevsky and others scholars. All these researchers noted a direct dependency of the quality of a performed work on the level of physical conditioning to the work's peculiarities, and also that this level shall be improved during the professional training of a student.

\section{Methods and materials}

In its turn, this task is divided into a number of subsequent narrower, applied tasks that together form and integrated whole:

- fostering a profound interest to the selected major, diligence, respect to and understanding of the value of physical fitness as one of the axiological aspect of the professional education, humanity, honesty, collectivism and cooperativeness in the collective;

- strengthening of health and complex prevention of acute and chronic illnesses, first of all, those of cardiovascular and nervous system, as well as psychic and psycho-emotional disorders caused by stressful situations arising during the professional life;

- development of a high level of working capacity, stamina, readiness to operation under extreme and nonstandard conditions;

- improvement of thermal regulation of the body, its vestibular, auditory and visual sensory system;

- development of skills and abilities of operative perception, operative thinking, preparedness to apply sports skills and abilities to applied tasks;

* Corresponding author: polykov.74@mail.ru 
- formation of an ability to control proportion of muscular activity, formation of stable trunk muscles, prevention of hypodynamia and early degenerative spinal phenomena, as well as formation of emotional stability, attention concentration, development of selfcontrol skills;

- development of communicative personal qualities in stressful and stressogenic conditions.

These tasks are determinant factors in preparation of curricula and lesson planning. We hold that PPPE and general physical education are related but still separate subjects, and this supposes a correct selection of forms and procedures for working with students depending on the nature of their future professional life.

\section{Results and Discussion}

Unfortunately, organization of PPPE in institutions of higher education presents severe difficulties currently. First of all, there are technical difficulties due to lack of material and technical possibilities for implementation of such training in all of its forms and types [2]. An important factor that inhibit PPPE implementation for students of institutions of higher technical education is a physical unpreparedness of many school leavers who while having basic idea of their future profession and having made an informed choice, are nevertheless insufficiently informed of all the physical aspects of such activity [3]. For example, selecting a profession of geologist and having a sincere interest in the matter, many school leavers have very sketchy understanding of the reality of field geological survey expedition.

The latter factor we deem as one of the principal ones, as the foundation of the physical education of the students of institutions of higher technical education is a multifaceted fitness training as it is defined by curriculum and credit test targets. In other words, PPPE is a secondary development with respect to the general physical training and is based upon it. The latter statement is a substantial one, as the foundation of physical education of students is their comprehensive physical training that is defined by curriculum and credit test targets for a given section of their physical education.

Currently, there are various methodological means for accomplishing the training of technical students that constitute a wide variety of forms and modalities for working with students in this direction [4].

One of such forms that is deemed important at the first stage of implementation is theoretical and practical training sessions in the form of lectures, workshops and independent projects that is the forms of student activity, which are the most common in the higher education environment. At this stage, the main objective of the instructor is to form a good understanding of correct use of the means of physical training with considerations for specifics of the professional peculiarities of each department and major that the students are educated in [5]. The theoretical knowledge is of great importance, as in many cases it is the only way for transmission of necessary applied knowledge about using sports means in the context of student's future profession to them [6]. Consequently, we mean lectures. However, on the other hand, such a lecture may be a one-off event, after which one may move to other forms of pedagogical control over mastery of knowledge: seminars, independent projects or testing; whereupon practical forms and procedures may be included into the teaching situation [7]. However, such a lecture shall necessary cover the following aspects:

- a short characteristics of various types of labor with extended description of psychophysical peculiarities of work of the future specialists of a given department;

- regularities in work capacity of a human being in the context of work of specialists of the given profile through different periods: working day, week, month, year;

- influence of age and climatic factors on work capacity of technical specialist;

- using the means of physical training and sport with the view of rejuvenescence of working ability and its improvement in the context of the working conditions, schedule and rotation of various works;

- basic methods of combating accumulated fatigue and preventing professional illnesses using physical exercises.

However, the methodology cannot be reduced to just theoretical and practical training: there shall be independent work of students during both class and extracurricular time. In the first case, it shall be a system of special physical exercises that uses previously developed credit test targets, active games, talks on propaganda of a healthy lifestyle and peculiarities of work under non-standard conditions; in the second case they shall be training sessions under professional coaches in sports clubs, on grounds, in recreation camps, etc..

However, we shall take into account the fact that the concept of technical education is a multidimensional one, being divided into a multitude of professions, from process engineer to test pilot. Each of these professions, e.g., pilot, geologist, surveyor, presupposes readiness to work under extreme condition due to arising emergencies, when the specialists needs to show not only a good judgment, distress tolerance and a sense of personal responsibility, but also readiness to make fast and correct decisions so that to prevent danger to their own life and health and that of other people depending on the orchestrated efforts of the specialist [8].

Within this context, one cannot speak about a separate methodology for students of institutions of higher technical education as a whole, but rather about a specific set of methodological formulas and procedures and specifics of academic activities in this direction as applied to a given technical major.

\section{Conclusions}

In this paper, we considered methodological peculiarities of professional-purpose physical training of students in an institution of higher technical education, its main 
forms and types. However, it should be noted, that both methodological and medical science lack a universal means for implementing such training. That is true even in cases where it considers training relevant to a given profession [9]. Here, the human factor is important: in other words, what kind of person we are teaching. In many cases, it is not a question of peculiarities of applied physical training, but rather that of whether the given person is able to work in this profession at all. Unfortunately, statistics reveals deplorable facts: the rate of chronic illnesses manifesting in childhood and during the adolescence is on the rise, which is especially true of spasmodic asthma, allergies of various types, diabetes, and congenital heart disease. Many of these illnesses are hereditary, though, in many cases, harmful environment, quality of food and prolonged disadvantageous life conditions plays a role of a provoking and aggravating factor. Consequently, such issues shall be resolved before applying to and enrolling in a university. This task is allotted to specialist doctors that conduct medical examination of the school leavers. At the same time, there is no denying that there is a very low number of people with ideal health, devoid of any physical disorders; however, the physical education and training are the thing that may increase resistance of the organism to disadvantageous external factors and help overcome existing illnesses. Exposure to physical education starts in early childhood, then continues during the school years and only then, as a final stage (if we are not speaking about professional sports as a career choice), in an institution of higher education. That is, physical education and training shall accompany a person throughout all stages of coming-of-age [10]. At that, PPPE shall become the final stage of education of a young adult. Only then, we may speak about its efficiency.

Currently, methodologists, medical specialists and physical education specialists actively develop training complexes for professional-purpose physical education of technical students that are based upon existing methodological foundation, analysis of vast experience and implementation of progressive training and healthmaintaining technologies.

\section{References}

1. O. Voitovska, \& S. Tolochko, Physical education teachers' perspectives in a changing world: from future studies to new physical culture, Philosophy and Cosmology, 20, 139-145, (2018) DOI: 10.29202/phil-cosm/20/13

2. A. Bestard-Revilla, \& E. Sivila-Jimenez, The scientific research in the formation of the professional of the Physical Culture $=\mathrm{La}$ investigación científica en la formación del profesional de la Cultura Física, Arrancada, 17(32), 202-214, (2017)

3. N.K. Gabdrakhmanov, R.A. Ulengov, \& R.R. Khadiullina, Research of the web websites ensuring availability in higher education institutions of physical culture in the conditions of athlete students inclusive training, Revista QUID (Special Issue), 1, 1334-1340, (2017)

4. G. Li, Analysis on the conceptual innovation of sports culture in international communication based on the values of physical education, AgroFOOD Industry Hi-tech, 28(3), 3486-3488, (2017)

5. R.R. Khadiullina, Implementation of the technology of educational process of student-athletes of different modes of study under the conditions of virtual educational environment of a physical culture higher school, Tomsk State University Journal, 420, 172-178, (2017). DOI: 10.17223/15617793/420/26

6. A.R. Milian, V.R. Aguilar, \& M.G. Pairol, The preparation of the teacher of physical culture in health and prevention: a way for the direction of the training of the graduate of the degree in education = La preparación del docente de cultura física en temas de salud y prevención: una vía para la dirección de la formación del egresado de la Licenciatura en Educación, Universidad y Sociedad, 9(3), 173-176, (2017)

7. R.M. Shaidullina, A.F. Amirov, V.S. Muhametshin, \& K.T. Tyncherov, Designing economic socialization system in the educational process of technological university, European Journal of Contemporary Education, 6 (1), 149-158, (2017) DOI: 10.13187/ejced.2017.1.1494

8. N.G. Khairullina, L.M. Gaisina, N.A. Krasulina, Z.Z. Berezhnova, \& A.V. Greb, International and Inregional premises of formation of the Labor market in Russia, Journal of Advanced Research in Law and Economics, 6(1), 247-255, (2015) DOI: $10.14505 /$ jarle.v6.1(11).25

9. L.M. Lara, \& E. Rich, The studies of physical culture at the university of Bath, United Kingdom: Dimensions of an approach that goes way beyond physicality $=$ Los estudios de cultura física en la universidad de bath - reino unido: Dimensiones de un enfoque mucho más allá de la fisicalidad, Movimento, 23(4), 1311-1324, (2017) DOI: $10.22456 / 1982-8918.74326$

10. A.Z. Ibatova, N.V. Ippolitova, S.K. Mukhametgaliyeva, A.E. Rodionova, Kh.N. Yagafarova, \& L.N. Ikonnikova, Lifelong Professional Education in the Russian Federation: Personal Aspect, International Journal of Environmental and Science Education, 11(16), 9426-9436, (2016) 